\title{
Adding intranasal fluticasone to cefuroxime resolved acute rhinosinusitis
}

Dolor RJ, Witsell DL, Helkamp AS, et al, for the Ceftin and Flonase for Sinusitis (CAFFS) Investigators. Comparison of cefuroxime with or without intranasal fluticasone for the treatment of rhinosinusitis. The CAFFS Trial: a randomized controlled trial.JAMA 2001 Dec 26;286:3097-105.

QUESTION: In patients with acute rhinosinusitis and a history of chronic or recurrent sinus symptoms, is the addition of intranasal fluticasone to cefuroxime more effective than the addition of placebo for prompting recovery?

\section{Design}

Randomised \{allocation concealed*\}†, blinded (clinicians, patients, data collectors and foutcome assessors $\} \uparrow$ ), , placebo controlled trial with 8 weeks of follow up.

\section{Setting}

12 primary care and 10 otolaryngology sites in the USA.

\section{Patients}

95 patients who were $\geqslant 18$ years of age (median age 38 to $41 \mathrm{y}, 68 \%$ women) with recurrent or chronic sinusitis requiring antibiotic treatment. All patients were required to have evidence of sinus infection on either plain film radiography or nasal endoscopy. Exclusion criteria were previous sinus surgery, sinus lavage in the previous 7 days, nasal polyposis, recurrent moderate epistaxis, chronic bacterial sinusitis with antimicrobial treatment failure, intranasal corticosteroid use in the previous 14 days, long term corticosteroid or immunosuppressive agent use, immunocompromised state, allergy to cephalosporins or penicillins, antibiotic use in the previous 7 days, or potential for pregnancy. 92 patients $(97 \%)$ were included in the analysis.

\section{Intervention}

All patients received cefuroxime axetil, $250 \mathrm{mg}$ twice daily for 10 days, and 2 puffs of xylometazoline hydrochloride per nostril twice daily for 3 days, after which they were allocated to fluticasone propionate, 2 puffs of $200 \mu \mathrm{g}(\mathrm{n}=47)$, or placebo $(\mathrm{n}=48)$ for 21 days.

\section{Main outcome measures}

Clinical success. Patients reported by telephone interview whether they were cured or much improved using a 6 point scale (cured, much improved, somewhat improved, no change, somewhat worse, and much worse). Secondary outcomes were health status and quality of life changes measured by the Sinonasal Outcome Test-20 (SNOT-20) and the Short Form-12 (SF-12).

\section{Main results}

Analysis was by intention to treat. More patients who received fluticasone than placebo achieved clinical success $(\mathrm{p}=0.009)$ (table) and reached it in fewer days (median 6.0 ข $9.5 \mathrm{~d}, \mathrm{p}=0.01$ ). The fluticasone and placebo groups did not differ for changes on the SNOT-20 (change from baseline to 56 days $-1.0 v-1.0, \mathrm{p}=0.54$ ) or changes on the SF-12 survey (change from baseline to day 21 physical component score $7.8 v 4.6, \mathrm{p}=0.39$, and mental component score $2.4 v 1.4, \mathrm{p}=0.21$ ).

\section{Conclusion}

In patients with acute rhinosinusitis and a history of chronic or recurrent sinus symptoms, the addition of intranasal fluticasone to cefuroxime was more effective than the addition of placebo in achieving cure or improvement.

*See glossary.

$\dagger$ Information provided by author.

Source of funding: GlaxoSmithKline.

For correspondence: Dr R J Dolor, Duke Clinical Research Institute, Durham North Carolina, USA. dolor001@mc.duke.edu.

Fluticasone v placebo added to cefuroxime for acute rhinosinusitis at 8 weeks

\begin{tabular}{lllll} 
Outcome & Fluticasone & Placebo & RBI (95\% CI) & NNT (CI) \\
Clinical success & $94 \%$ & $74 \%$ & $27 \%(6$ to 58$)$ & 6 (3 to 19) \\
\hline
\end{tabular}

$\ddagger$ Abbreviations defined in glossary; $\mathrm{Cl}$ for RBI calculated from data in article.

\section{COMMENTARY}

In the USA, an estimated 3 million patients per year are treated for symptoms suggestive of acute rhinosinusitis. ${ }^{1}$ Currently, physicians are advised to diagnose the condition by clinical criteria ${ }^{1}$ and to use amoxicillin or trimethoprim-sulfamethoxazole as first-line treatment agents. ${ }^{2}$ Such adjunctive agents as topical decongestants and corticosteroids have been considered by many to be useful but have been less thoroughly investigated than have antibiotics. ${ }^{2}$

The patients in the study by Dolor et al were not previously healthy people with an isolated episode of acute sinusitis. A third to a half had a known diagnosis of allergic illness in addition to recurrent or chronic sinusitis. About a quarter showed only mucosal thickening on radiography (Dolor RJ, personal communication): a finding that is nonspecific and often seen in allergic or viral illness. ${ }^{3}$

This study does not prove that fluticasone speeds resolution of acute bacterial sinusitis unrelated to atopy. However, these conditions frequently coexist, and differentiating between them may be difficult. The addition of fluticasone (and perhaps 3 days of xylometazoline) to first-line antibiotics in clinically diagnosed sinusitis is now a better validated option, especially if a history of recurrent episodes or underlying allergy exists.

Laura R Willett, MD Robert Wood Johnson Medical School New Brunswick, New Jersey USA

1 Balk EM, Zucker DR, Engels EA, et al. Strategies for diagnosing and treating suspected acute bacterial sinusitis. J Gen Intern Med 2001;16:701-11.

2 Lau J, Zucker D, Engels EA, et al. Diagnosis and treatment of acute bacterial rhinosinusitis. Evidence Report/Technology Assessment no. 9. AHCPR publication no. 99-E016. Rockville: Agency for Health Care Policy and Research, Mar 1999 (www.ahcpr.gov/clinic/ sinussum.htm).

3 Willett LR, Carson JL, Williams JW Jr. Current diagnosis and management of sinusitis. J Gen Intern Med 1994;9:38-45. 